\title{
"Un Lautréamont Negativo": Tradición y Política en la Interpretación Benjaminiana de Kafka
}

\author{
['A Negative Lautréamont': Tradition and Politics in Benjamin's Interpretation of Kafka] \\ http://dx.doi.org/10.1590/1982-88371826121
}

\section{María Belforte ${ }^{1}$}

\begin{abstract}
This article is intended to analyze Benjamin's interpretation of Kafka from the perspective of tradition. The revision of the said concept is here studied whithin the context of Benjaminian late works. The notions of aggadah and halacha are then central for the structure of his reflections. Thus, this paper aims at tracking the elements involved in the elaboration of a political theory that allowed Benjamin to recover Kafka for his political renewal of the concept of humanity.
\end{abstract}

Keywords: tradition; politics; materialism; mysticism.

Resumen: El presente artículo se propone analizar la interpretación benjaminiana de Kafka tomando como eje central el problema de la tradición y su resignificación política en el contexto de producción tardío. Son relevantes en este sentido, los conceptos de hagadá y halajá con los que Benjamin estructura sus análisis. El objetivo es entonces rastrear los elementos que en la elaboración de una teoría política permiten recuperar al narrador checo para la revisión de un concepto de lo humano.

Palabras clave: tradición; política; materialismo; misticismo.

\section{El planteo teológico del problema de la tradición}

Como muestra Daniel WEIDNER, el problema de la tradición en Benjamin aparece muy tempranamente en sus escritos y ya se plantea asociado al concepto de Erfahrung en

\footnotetext{
${ }^{1}$ Universidad de Buenos Aires (UBA), Consejo Nacional de Investigaciones Científicas y Técnicas (CONICET), Instituto de Filología y Literaturas Hispánicas Dr. Amado Alonso, 25 de mayo 217, $1^{\circ}$ piso, C1002ABE, Ciudad Autónoma de Buenos Aires, Argentina. Email: mariabelforte@yahoo.com 
"Über das Programm der kommenden Philosophie" de 1917 en donde se muestra inseparable de la noción de "Lehre" que Scholem y Benjamin discuten por aquellos años (cf. WeIDNER 2006: 36s.). Weidner delinea las distintas posiciones de los dos amigos y sostiene que, para Benjamin, la "esfera religiosa" no es algo natural y evidente sino, por el contrario, algo profundamente problemático (ibíd.: 37 ). ${ }^{2}$ Es en tanto tema problemático que entra en relación con un proyecto como el que tiene lugar a fines de 1920 en el derrotero intelectual de Benjamin.

La relación con Scholem es relevante debido a la distinción que Benjamin comparte con su amigo respecto de la noción de tradición, en oposición a ciertas tendencias nacionalistas ${ }^{3}$ de las que se encuentra alejado. Si el interés de Benjamin por la mística judía adquiere significación y fija un marco metodológico incluso en sus trabajos tardíos de orientación marxista, esto se debe a que el fundamento de la misma se encontraba para estos pensadores en el concepto de tradición. Así, Benjamin recupera de Scholem la fundamentación del judaísmo en dicho concepto y no en el de "nación", "vivencia" o "fe" (íd.). ${ }^{4}$ Surge del diálogo temprano con Scholem un elemento teórico esencial para la construcción de un programa político en el pensamiento benjaminiano: la noción de "tarea" (Aufgabe) que es significativa en el contexto del acercamiento a la tradición que los amigos se plantean. SCHOLEM escribe: "El comentario es un concepto ordenador (Ordnungsbegriff) del mundo espiritual del judaísmo. Representa la última tarea". Se ve aquí la marca de un pensamiento que nutrirá la metodología de trabajo de Benjamin hasta sus últimos escritos; la esencia del mundo de esta concepción es el lenguaje y la escritura (íd.) que se verá plasmada también en el proyecto de los pasajes y

${ }^{2}$ El autor señala que incluso Scholem aborda la cuestión de la doctrina religiosa de manera poco tradicional: "Für beide ist die Lehre kein stabiler Grund oder ein stetiger Strom, sondern eben ein sturmgepeitschtes Meer" (WEIDNER 2006: 37).

${ }^{3}$ Las tendencias nacionalistas con las que Benjamin dialoga, explícita o implícitamente, corresponden a posiciones intelectuales de derecha pero también a intelectuales más afines a su círculo de juventud como en el caso de Martin Buber.

${ }^{4}$ Cabe destacar la insuperable distancia de Benjamin con Buber en lo que respecta a la noción de "Erlebnis" y sus connotaciones filosófico-políticas. Cf. al respecto SCHOLEM 2008: 36 y 67.

${ }^{5}$ SCHOLEM, Tagebücher, vol. 2, 198, citado en WEIDNER, 2006: 37 (la trad. es mía). En una anotación temprana de 1917 (GS VI: 51-52), BENJAMIN analiza la noción de tarea infinita (unendliche Aufgabe) en dos sentidos: como fundamento de la autonomía y del método. En este contexto, Benjamin concibe la autonomía de la ciencia en relación con la infinitud de cuestiones sobre el mundo y el ser, que ésta no precisa plantearse para constituirse como tal. Más bien la ciencia es una forma de dicha tarea infinita: "Die Wissenschaft ist eine ihrer Form nach (nicht ihrer Materie nach) unendliche Aufgabe" (GS VI: 51). Por otra parte, en esta época temprana, la unidad de la ciencia existe para Benjamin en la infinitud de su tarea.

Pandaemonium, São Paulo, v. 18, n. 26, Dez. /2015, pp. 1-21 
en el concepto de imagen dialéctica, central en el mismo. La noción de comentario como última tarea constituye el anticipo de una concepción como la de Das PassagenWerk en la que la impronta de la tarea adquiere un carácter político por su contenido programático. Benjamin retoma allí las formas de esta tradición que lo impactan en su juventud para suministrarles un contenido que transforma el trabajo historiográfico en un proyecto político.

Cabe tener en cuenta, entonces, el doble sentido presente en el concepto de doctrina que señala Weidner, si se intenta recomponer la estructura metodológica y argumentativa de los planteos políticos de Benjamin en los últimos años. Así, Lehre implica, en el contexto de la discusión con Scholem, un contenido y un proceso, un abordaje esotérico y uno exotérico, una transmisión escrita y una oral. El criterio de Benjamin es el siguiente: de ambas tendencias de la doctrina, él conservará la que resulte más dinámica para un pensamiento transformador: el proceso. Pero dicho proceso debería adaptarse a las formas secularizadas de la Modernidad en las que la transmisión no se plantea como ritual oral sino como escritura: lo esotérico por naturaleza, el proceso de la doctrina se vuelve interior y adquiere nuevos contenidos que, aunque también misteriosos, no son ya metafísicos sino materialistas. La verdad no se encontrará entonces en ninguna idea, sino en el producto histórico de una forma de producción con sus deseos ocultos y objetivados. Ciertas orientaciones del pensamiento místico judío determinan la concepción materialista de la política como tarea, como comentario y como aprendizaje dado por la experiencia, en el contexto de Das Passagen-Werk. Por otra parte, la idea de Scholem de que la tradición escrita es la paradoja en la que la literatura judía se despliega (ibíd.: 38) se plasmará en los análisis tardíos de Benjamin y constituirá una posible justificación de la relevancia que adquiere para él la figura de Kafka en el marco de planificación de Das Passagen-Werk. 


\section{Lectura de Kafka: un modelo de crítica al mito desde la literatura}

El primer testimonio del vínculo de Benjamin con la obra de Kafka, lo encuentra Scholem en una carta que su amigo le envía en julio de 1925 (GS II/3: 1153). Aunque el estudio del escritor checo propiamente dicho no comienza en una época temprana, Benjamin se interesa por la obra de Kafka en un punto de viraje de sus intereses. ${ }^{6}$ La fascinación de Benjamin por Kafka se prueba no solamente con las abundantes referencias que aparecen en sus cartas y los proyectos inconclusos sobre el autor, ${ }^{7}$ sino también con la explícita afirmación de BENJAMIN: "Als Krankenengel habe ich an meinen Lager Kafka. Ich lese den 'Prozeß"' (II/3: 1154). ${ }^{8}$ Los estudios sobre Kafka constituyen una referencia destacada para el análisis del concepto de tradición en Benjamin, como sostiene Sigrid WeIGEL (2006), dado que sus historias hablan del proceso de degradación o enfermedad de la tradición (Erkrankung der Tradition). ${ }^{9}$ Los análisis de la obra y la figura de Kafka sobrepasan en extensión las únicas dos contribuciones publicadas en vida por Benjamin: el breve artículo "Kavaliersmoral", aparecido en la Literarische Welt en 1929, y los dos capítulos de su ensayo "Franz Kafka. Zur zehnten Wiederkehr seines Todestages", aparecido en la Jüdische Rundschau en 1934. También da Benjamin en 1931 una conferencia radial titulada “Franz Kafka: Beim Bau der Chinesischen Mauer". Por otra parte, los planes de editar

\footnotetext{
${ }^{6}$ Aunque son muchos los elementos a tener en cuenta en este sentido, basta recordar la influyente lectura de Geschichte und Klassenbewußtsein y el viaje a Moscú para reconocer este momento de transición a mediados de los años veinte.

${ }^{7}$ Como demuestra Weigel, la lectura de Kafka llevada a cabo por Benjamin abarca un amplio período que va de 1925 a 1935 y que corre paralelo a los escritos sobre el autor, desde 1927 a 1938 (cf. WEIGEL 2006: 546).

${ }^{8}$ Como lo muestra la lista de libros elaborada por Benjamin, también habría leído entre mayo y junio de 1931, Amerika, Das Schloss, Betrachtung (en París entre octubre de 1933 y junio de 1934, según la entrada 1177 de la lista) y el libro de Hellmuth Kaiser Franz Kafkas Inferno (GS VII/1: 464). Luego, en París, entre 1933 y 1934 lee Das Urteil y Die Verwandlung (GS VII/1: 468). Der Prozeß aparece antes, con el número 1059 de la lista (GS VII/1: 459). También el manuscrito 967 constituye una prueba del estudio acabado de Kafka en cuanto, bajo el título "Bibliograhie zu Kafka", Benjamin enumera más de una veintena de análisis que le interesan en relación con el autor (GS II/3: 1247).

9 También afirma: "Das Werk von Kafka: die Erkrankung des gesunden Menschverstandes. Auch des Sprichworts" (GS II/3: 1193). Respecto a la noción de enfermedad de la tradición, cf. el análisis de HANSSEN y su vínculo con la figura de poeta fracasado sobre la que volveremos más adelante (2000: 140s.).
} 
un libro sobre "Kafka, Proust, etc.”, datan de 1928 (cf. WEIGEL 2006: 543) y muestran una coincidencia temporal con los inicios del proyecto sobre los pasajes.

Además de la íntima conexión con el problema de la tradición, la dedicación al estudio de Kafka en los años treinta constituye una excepción a la tendencia materialista presente en los ensayos de esa época. Esta tensión o ambivalencia puede interpretarse como un aporte disruptivo en el proyecto de los pasajes que tomaba forma por aquellos años. Aunque las nociones que aparecen en el proyecto son herederas de las reflexiones y conceptos utilizados en los análisis sobre el escritor checo, las referencias explícitas a Kafka en Das Passagen-Werk no son numerosas. ${ }^{10}$

En un esquema de análisis anterior al ensayo de $1934^{11}$ (GS II/3: 1192), Benjamin interpreta la obra de Kafka como una contraposición dicotómica en la que se presentan dos mundos: el mundo primitivo y el de la ley escrita del judaísmo. El primero, previo a la escritura de la ley es, según Benjamin, el mundo de la culpa, etapa perdida en la que lo olvidado no constituye algo exclusivamente individual. A este Sumpfwelt se enfrenta en Kafka, no el mundo del presente moderno, sino el de la justicia, el del derecho que no se practica, el del judaísmo (íd.). Así, confrontados el momento histórico hetáirico y el de la ley judía, Benjamin construye en este esbozo una escisión que será superada luego en su ensayo de $1934 .{ }^{12}$ Aquí, el tiempo presente no entra en relación, según Benjamin, con estas dos etapas humanas. En este intento de estudio de Kafka, la época contemporánea queda fuera de análisis, a diferencia de lo que será luego un elemento central para la construcción de la noción de experiencia en Kafka y su confrontación entre la experiencia mística y la moderna. La introducción del análisis de los fenómenos modernos en el marco del estudio de Kafka, que aparece en su ensayo de 1934, pero también en su crítica a la interpretación de Brod, da un giro a los planteos esbozados aquí con anterioridad. Lo que Benjamin establece en este caso es una relación que recupera reiteradas veces: la de la halajá y la hagadá. Tomada de

\footnotetext{
${ }^{10}$ En las anotaciones tempranas existen referencias a Der Prozeß (GS V/2: 1010) y a imágenes asociadas a Kafka (GS V/2: 1018 y 1036).

${ }^{11}$ Aunque la fecha de este esquema no está definida, los editores consideran que no fue escrito con posterioridad a 1931.

${ }^{12}$ BENJAMIN afirma aquí: "Kafkas Romane spielen in einer Sumpfwelt. Diese Welt ist es, und nicht die unsrige, die Kafka in seinen Büchern mit der gesetzlichen des Judentums konfrontiert” (GS II/3: 1192).
} 
Chaim Nachman Bialik, como lo muestra su correspondencia con Scholem, ${ }^{13}$ la distinción permite a Benjamin diferenciar la prescripción de la narración y de esta forma, establecer una correspondencia entre la transmisión de la tradición y su contenido. Lo que hace Kafka según Benjamin es darles palabra a las huellas del mundo primitivo que se encuentran en la halajá del mundo judaico: "Mit andern Worten: nur die Halacha enthält noch Spuren dieser fernsten Daseinsart der Menschheit. Kafkas Bücher enthalten die fehlende Hagada zu dieser Halacha” (íd.). Benjamin interpreta la culpa como esa existencia primitiva en el mundo de la ley que describe Kafka. Ésta posee un elemento existencial que le permite a BENJAMIN leer el castigo como enfrentamiento entre los dos mundos: "Dem hetärischen Natursein der Menschheit hält das Judentum die Strafe entgegen” (íd.). La lectura de Benjamin todavía no posee un elemento dialéctico que ayude a reconocer el mundo del mito como parte del presente. Contrapone lo primitivo y la culpa con la ley y la justicia de un derecho que no se practica. Es en la etapa de la ley en donde Benjamin interpreta la aparición de las huellas del pasado caído del hombre. Pero este pasado tiene el elemento propio de la acción, de una práctica que es enfrentada con la teoría del derecho que no se ejerce: frente a la culpa de la acción pecaminosa y mugrienta, el mundo de Kafka abre el espacio a una profecía, la profecía de la redención. El último párrafo de este análisis sostiene: "Die Gegenwart, unsere gewohnteste Umwelt, scheidet also für Kafka vollkommen aus. Sein ganzes Interesse gilt in Wirklichkeit dem Neuen, der Strafe, in deren Lichte freilich die Schuld schon zur ersten Stufe der Erlösung wird” (íd.). El mito se enfrenta con la justicia, con la ley de la palabra escrita, del derecho exento de praxis. Benjamin aún no alcanza a descubrir el elemento dialéctico en las narraciones del poeta checo que indicará en 1934. Allí entra en juego el universo del cuento maravilloso que identifica con las narraciones kafkianas: éstas son "Märchen für Dialektiker” (GS II/2: 415). Encuentra en este género una posible respuesta al mito, ${ }^{14}$ una forma de la narración que incorpora la razón y la astucia que interesan a Benjamin para su proyecto

\footnotetext{
${ }^{13}$ Benjamin escribe a Scholem que necesita leer con cierta urgencia el artículo de Chaim Nachman Bialik "Hagadah und Halacha" por lo que le pide que se lo envíe en una carta escrita el 11 de agosto de 1934. Hace nuevamente referencia a este trabajo en otra carta de septiembre del mismo año (BENJAMIN/SCHOLEM 1980: 166 y 172).

${ }^{14}$ En su ensayo sostiene: "Vernunft und List hat Finten in den Mythos eingelegt; seine Gewalten hören auf, unbezwinglich zu sein. Das Märchen ist die Überlieferung vom Siege über sie” (GS II/2: 415). 
político de los pasajes. El ejemplo que toma es el del mito de Odiseo reformulado por Kafka en "Das Schweigen der Sirenen” (1917). Según Benjamin: "Odysseus steht ja an der Schwelle, die Mythos und Märchen trennt” (GS II/2: 415). Kafka posee la astucia de desarmar la estructura mítica al incorporar el elemento del cuento maravilloso; su narración renuncia al lugar que tenía en la tradición sobre la que se sostiene el mito. Es aquí la capacidad creativa de las palabras la que tiene preeminencia sobre la doctrina; el de Kafka fue, según Benjamin, un incomparable esfuerzo de traducir la poesía en enseñanza. ${ }^{15}$ La poesía que se pone en juego en este ensayo es, sin embargo, una poesía que traduce la experiencia, no solamente de un mundo trascendente, sino también inmanente. Por eso es que en este trabajo, a diferencia de lo que se observa en los primeros esbozos de análisis, se destaca la preocupación por la experiencia del presente de la Modernidad que encuentra en la obra de Kafka.

La interpretación de Kafka como fracasado, en la que Benjamin insiste, tiene su origen en la lectura del poeta como aquel que más se preocupó por la renuncia a la fabricación de imágenes (GS II/2: 428). Así, el rechazo de la imagen representativa divina de la tradición judía coincide con la desconfianza política que muestra Benjamin por la mediación política representativa. ${ }^{16}$ La mediación de la representación rechazada por Benjamin solamente es recuperada en una instancia particular que implica un análisis dialéctico y político. La imagen que Benjamin construye en oposición a la representativa es la imagen dialéctica que no sustituye algo sustantivo por su copia, sino que crea una realidad nueva a partir de la destrucción de lo pasado. En esta dirección se encamina su interés por la obra de Kafka: su mundo de imágenes no representa, sino crea una realidad que revela aquello que el olvido mantiene latente en las deformaciones del espacio y el tiempo.

En los trabajos de Kafka, Benjamin encuentra la mirada del que ve la catástrofe y el fracaso respecto de la Modernidad. Tanto en uno como en otro, la pregunta acerca de la tradición y sus posibilidades de transmisión adquiere un carácter central. De allí la

\footnotetext{
15 BENJAMIN afirma en 1934: "Gescheitert ist sein großartiger Versuch, die Dichtung in die Lehre zu überführen und als Parabel ihr die Haltbarkeit und die Unscheinbarkeit zurückzugeben, die im Angesicht der Vernunft ihm als die einzig geziemende erschienen ist" (GS II/2: 427s.).

16 En relación con la noción de "das Ausdrucklose" que aparece en el ensayo sobre Wahlverwandtschaften e implícitamente en muchos análisis benjaminianos, cf. MENNINGHAUS 1993.
} 
importancia dada por Benjamin y Kafka a la mística judía, que permea los escritos de ambos. Así, por ejemplo, la noción de umbral destacada en la obra de Kafka adquiere un lugar significativo en Das Passagen-Werk, lo cual permite preguntarse por la influencia de la temática de la tradición y los análisis sobre Kafka en el contexto político del proyecto. No solo por el valor heurístico que esta noción presenta en relación con conceptos como los de transitoriedad, tarea o tradición, sino también debido a la atención que tanto Benjamin como Kafka le prestaron a la imagen misma de umbral. ${ }^{17}$ La imagen surge reiteradas veces en Das Passagen-Werk, donde aparece el término "Schwellenerfahrungen"18 que adquiere un sentido propio en el marco de la crítica a la experiencia. Además, el estudio sobre las galerías de París contiene referencias a las entradas y los pasajes que implícitamente refieren a este espacio intermedio que antecede las puertas de acceso a una nueva dimensión.

Una de las claves para descubrir la problemática de la tradición que Benjamin recupera en la figura del escritor checo se encuentra en la carta enviada a Scholem en la que rechaza la lectura que Brod hace de Kafka. En esta carta del 12 de junio de 1938, Benjamin cita un pasaje del astrofísico Arthur S. Eddington en la que se analiza, con una humorada, la condición de umbral desde una perspectiva científica. ${ }^{19}$ Benjamin

\footnotetext{
${ }^{17}$ Es también como parte de la embestida contra el libro de Brod sobre Kafka que BENJAMIN argumenta: "Infolge eines auffallenden Mangels an Takt, an Sinn für Schwellen und Distanzen fließen Feuilletonschablonen in einen Text ein..." (BENJAMIN/SCHOLEM, 1980: 267).

${ }^{18}$ En Das Passagen-Werk I1a, 4 aparece asimismo el sustantivo compuesto Schwellenzauber, magia de los umbrales (GS V/1: 283). También en C3,5, Benjamin escribe: "Der despotische Schrecken der Klingel, der über der Wohnung waltet, hat seine Kraft ebenfalls aus dem Zauber der Schwelle" (GS V/1: 141). Cf. asimismo C 8,1 (GS V/1: 152) y S 9,4 (GS V/2: 694) en donde se hace referencia al umbral de la conciencia. La imagen del umbral sirve a Benjamin, como se aprecia en todos estos pasajes, como metáfora de pasaje tanto espacial como temporal y consciente. Ya en las primeras anotaciones connota un momento de detención, de espera, en la entrada a los pasajes: "Diese Tore sind auch Schwellen", sostiene BENJAMIN (GS V/2: 1031). La imagen es reiterada en muchos otros trabajos: en Berliner Kindheit donde se habla de "die Schwelle zwischen Traum und Wirklichkeit" (GS VII: 423), aparece también en el ensayo sobre Proust (GS II/1: 320), en el de Kraus (GS II/1: 348, 349, 362), y en las anotaciones sobre Kafka (GS II/3: 1261), entre otros. Si bien no existe una unidad acabada del sentido de cada una de estas imágenes, todas ellas convergen en las ideas dialécticas de pasaje y detención.

${ }^{19}$ Algunos pasajes del texto de Eddington citado por Benjamin resultan ilustrativos del planteo: "Ich stehe auf der Türschwelle, im Begriffe, mein Zimmer zu betreten. Das ist ein kompliziertes Unternehmen. Erstens muß ich gegen die Atmosphäre ankämpfen, die mit einer Kampf von I Kilogramm auf jedes Quadratzentimeter meines Körpers drückt. Ferner muß ich auf einem Brett zu landen versuchen, das mit einer Geschwindigkeit von 30 Kilometer in der Sekunde um die Sonne fliegt; nur den Bruchteil einer Sekunde Verspätung, und das Brett ist bereits meilenweit entfernt. [...] Wahrlich, es ist leichter, daß ein Kamel durch ein Nadelöhr gehe denn daß ein Physiker eine Türschwelle überschreite. Handle es sich um ein Scheunentor oder einen Kirchturm, vielleicht wäre es weiser, er fände sich damit ab, nur ein gewöhnlicher Mensch zu sein, und ginge einfach hindurch, anstatt zu warten, bis alle Schwierigkeiten
} 
encuentra en el cinismo del análisis del científico el mismo gesto kafkiano respecto de la realidad. La experiencia de pasaje cotidiano que todo umbral pone a prueba es presentada como una aporía tanto desde la literatura como desde la ciencia. Pero esa aporía en Kafka es resultado de la introducción de la experiencia mística, de la experiencia de la tradición en el contexto de las experiencias modernas. Así, escribe Benjamin: "Kafka lebt in einer komplementaren Welt" (BENJAMIN/SCHOLEM 1980: 271). Esa complementariedad a la que se refiere es precisamente el factor aportado por la tradición (íd.). En esta instancia, Benjamin encuentra un caso único en la literatura de Kafka en lo relativo a la tradición y a la concepción de experiencia por dicha tradición implicada:

Es ist das eigentlich und im präzisen Sinne Tolle an Kafka, daß diese allerjüngste Erfahrungswelt ihm gerade durch die mystische Tradition zugetragen wurde. Das ist natürlich nicht ohne verheerende Vorgänge (auf die ich sogleich komme), innerhalb dieser Tradition möglich gewesen (íd.).

Lo que le interesa a Benjamin de la literatura de Kafka es la peculiaridad con que la tradición es despojada del contenido doctrinario para establecer una nueva forma de experiencia que, de manera aporética, enfrenta la realidad de la experiencia del mundo actual. Así como la ciencia, en su formulación analítica de lo real, descompone los elementos de la experiencia hasta poner en jaque la más mínima posibilidad de acción cotidiana, también la tradición, desprovista de su contenido doctrinario, se muestra como una herramienta de revelamiento de las complejidades de la experiencia moderna. ${ }^{20}$ Benjamin afirma la ruptura de la constelación tradición-narración-verdad sobre la que la obra de Kafka se sostiene, e identifica la verdad épica, a la que se refiere en "Der Erzähler" con la verdad hagádica. Es entonces el concepto mismo de sabiduría lo que se encuentra en la base de su análisis: "Damit ist die Weisheit, als ein Traditionsgut gekennzeichnet; sie ist die Wahrheit in ihrer hagadischen Konsistenz" (ibíd.: 272). El saber de la tradición entra en crisis con el proceso de secularización; el contenido del saber de la ciencia muestra la misma forma experiencial que la tradición vaciada de contenido doctrinario. Es decir, Benjamin muestra que en el mundo kafkiano

sich gelöst haben, die mit einem wissenschaftlich einwandfreien Eintritt verbunden sind" (BENJAMIN/SCHOLEM 1980: 270s.).

${ }^{20}$ De allí que Benjamin presente la obra kafkiana como una decadencia o proceso de enfermedad de la tradición. Cf. supra, nota 9. 
tanto la ciencia como la tradición, en su forma no sustantiva, ponen en juego una dimensión de la verdad que se sostiene en su transmisibilidad. Esa transmisibilidad del saber cuyo contenido empírico-matemático de la ciencia moderna, o religiosodoctrinario de la tradición, se percibe en el instante de la acción consciente, puede poner en peligro la capacidad de praxis en la realidad moderna, al amenazar con descomponer la experiencia en instantes vividos sin continuidad.

El saber analítico de la ciencia, como la doctrina de la verdad a la que la literatura de Kafka se enfrenta, interrumpen la transmisibilidad de la verdad en la realidad secularizada de la Modernidad. Se trata entonces de transmitir un infinito (de conocimiento para la ciencia, de vacío para la tradición). Kafka representa en su hagadá que el infinito del saber al que aspira la ciencia moderna posee un sinsentido equiparable con el vacío de la ausencia de la doctrina.

Una respuesta a este vacío se encuentra en hacer de lo transitorio, que ya no es subsumido en el relato de la verdad, una forma en sí misma. Los "cuentos de hadas para dialécticos" de la literatura de Kafka poseen esa fórmula que interesa a Benjamin. También distintas imágenes, como la del umbral, representan esta transitoriedad. La imagen del umbral, como metáfora del instante de pasaje, está presente en Kafka: su literatura y sus diarios muestran la importancia dada por el narrador checo a esta imagen. Según Löwy, "varios pasajes del Diario sugieren que, para Kafka, el hecho de cruzar un umbral o el acto de 'forzar la puerta' era una especie de alegoría de la autoafirmación del individuo y de su libertad" (LÖWY 2007: 100). Los análisis llevan de esta manera a concebir la interpretación benjaminiana de Kafka en el contexto de una construcción teórica política, en la que el concepto de tradición es estudiado desde el punto de vista de la experiencia del presente.

\section{El concepto de tradición en el marco de una teoría política}

En las primeras anotaciones para Das Passagen-Werk, Benjamin escribe: "Was wäre das 19te Jahrhundert uns, wenn Tradition uns mit ihm verbände?" (GS V/2: 998). La pregunta es consecuencia de una afirmación relevante para la construcción de una teoría

Pandaemonium, São Paulo, v. 18, n. 26, Dez. /2015, pp. 1-21 
política en el siglo XX: "Kräfte der Ruhe (der Tradition) die aus dem 19ten Jahrhundert hinüberwirken. Verstellte historische Traditionskräfte" (íd.). Benjamin se plantea el problema de la tradición como un problema político; lo imprescindible es dar cuenta de la herencia recibida: "Rechenschaft vom unmittelbar überkommenen Erbe zu geben, ist wichtig" (íd.). Para dicha construcción es tarea de la crítica materialista la revisión de los valores e ideas transmitidas y conformadas en una unidad que es la que constituye la tradición.

Con este propósito, Benjamin destaca al respecto, desde la perspectiva del materialismo histórico, la existencia de dos tradiciones con características distintas. La tradición de la clase dominante está situada en oposición a la de los oprimidos ya que para la primera, la idea que la rige es la de discontinuidad, mientras que para la segunda es la idea de continuidad la que regula su tradición (GS V/1: 459s.). Esta continuidad está dada por la velocidad que diferencia a una y otra clase: el proletariado vive más lentamente que la burguesía (ibíd.: 460). El envejecimiento de las ideas de los oprimidos llega más tarde que el de las ideas de la burguesía; la ideología de ésta se manifiesta con las características propias de la moda, en la que lo viejo aparece como lo nuevo de manera velada.

De esta forma, el problema de la tradición es un problema político para el materialismo histórico, ya que constituye la base ideológica que construye la conciencia histórica de clase. Un fragmento de Das Passagen-Werk conserva el núcleo de la crítica a la tradición de BENJAMIN:

In der Idee der ewigen Wiederkunft überschlägt der Historismus des 19ten Jahrhunderts sich selbst. Ihr zufolge wird jede Überlieferung, auch die jüngste, zu der von etwas, was sich schon in der unvordenklichen Nacht der Zeiten abgespielt hat. Die Tradition nimmt damit den Charakter einer Phantasmagorie an, in der die Urgeschichte in modernster Ausstaffierung über die Bretter geht (GS V/1: 174).

El hecho de que la tradición haya perdido su vínculo con lo sagrado la expone a esta secularización fantasmagórica: sólo se aleja para volver en el mito de la razón y en la ausencia existencial de sentido. La narración de la historia de la tradición, que cimentaba su discurso a través de la experiencia, es ahora una forma vacía que permite la construcción ideológica de un pasado continuo, homogéneo y progresivo. 
Tal como aparece en una anotación de Das Passagen-Werk (GS V/1: 595s.), los fundamentos de la doctrina del materialismo histórico se sustentan, entre otros elementos, en la crítica al progreso en la historia así como en la experiencia, el sano sentido común (gesunder Menschenverstand), la dialéctica y la presencia de espíritu (Geistesgegenwart). Estos fundamentos para la construcción crítica de un modelo de materialismo histórico alternativo al mecanicista socavan la concepción de tradición heredada para poner al descubierto su estructura operativa ideológica. El eje temporal en el que Benjamin basa su crítica a la tradición es el presente: lo transmitido por la tradición pierde, en el modelo del proyecto de los pasajes, su preeminencia sobre el presente. En otras palabras, lo histórico abre paso a lo político. Benjamin escribe:

[Denn] das destruktive Moment in der materialistischen Geschichtsschreibung ist als Reaktion auf eine Gefahrenkonstellation zu begreifen, die sowohl dem Überlieferten wie dem Empfänger der Überlieferung droht. Dieser Gefahrenkonstellation tritt die materialistische Geschichsdarstellung entgegen; in ihr besteht ihre Aktualität, an ihr hat sie ihre Geistesgegenwart zu bewähren (GS V/1: 594s.).

El escape del ámbito del pensamiento del que habla aquí Benjamin (íd.) remite a la noción de Geistesgegenwart, ese estado de la conciencia y del cuerpo ${ }^{21}$ que resiste la tendencia interpretativa dominante del pasado en la que el presente no posee actualidad; una forma de enfrentamiento que lleva a la acción. La constelación de peligros a la que se refiere debe ser neutralizada por medio de la discontinuidad: "Damit ein Stück Vergangenheit von der Aktualität betroffen werde, darf keine Kontinuität zwischen ihnen bestehen" (GS V/1: 587). De este modo, la continuidad de la transmisión propia de la tradición de los oprimidos debe ser interrumpida y reformulada a partir de una nueva forma intermitente que haga presente el pasado desde una perspectiva disruptiva de las interpretaciones heredadas. La apelación a lo eterno de la tradición se presenta entonces interrumpida en su linealidad para mostrar su transitoriedad y contingencia. Ese es un aspecto de la actualización del pasado que el proyecto sobre los pasajes se propone. En una carta a Hofmannsthal del 8 de febrero de 1928, BENJAMIN, haciendo referencia a Einbahnstraße lo explica:

\footnotetext{
${ }^{21}$ La especial relación con lo corporal que esta noción implica se muestra con evidencia en un fragmento de Einbahnstraße titulado "Madame Ariane zweiter Hof links", cf. GS IV/1: 141s. 
Gerade in seinen exzentrischen Elementen ist das Buch wenn nicht Trophäe so doch Dokument eines inneren Kampfes, von dem der Gegenstand sich in die Worte fassen ließe: Die Aktualität als den Revers des Ewigen in der Geschichte zu erfassen und von dieser verdeckten Seite der Medaille den Abdruck zu nehmen. Im übrigen ist das Buch in vielem Paris verpflichtet, der erste Versuch meiner Auseinandersetzung mit dieser Stadt. Ich setze ihn in einer zweiten Arbeit fort, die "Pariser Passagen" heißt (GS V/2: 1083).

Lo que Benjamin aborda como el problema de la tradición no es entonces más que la transmisión de la interpretación mitificada del pasado que se presenta en el proceso de secularización, escondida en una matriz científica de la historia. Las sociedades tradicionales construían en sus narraciones una apariencia del mundo en que la experiencia de lo humano tenía lugar en sus muchas dimensiones. Al secularizarse la concepción del pasado, la narración historiográfica cae en manos de la eternidad de la ciencia dominante, que construye la interpretación del pasado como herencia legitimadora de las injusticias del presente. De allí que esta tradición sea interpretada como catástrofe: la ruina de la humanidad termina siendo justificada en una narración del pasado que domina el presente.

Ya en su libro sobre el Trauerspiel, Benjamin se plantea el problema de la separación entre hombres y cosas. Ese "salvar a los fenómenos" al que refiere allí será retomado en el contexto del análisis de los pasajes desde una perspectiva política: el eje alrededor del cual centra sus reflexiones no es ya una forma literaria, sino un producto histórico, la mercancía. Benjamin escribe:

Wovor werden die Phänomene gerettet? Nicht nur, und nicht sowohl vor dem Verruf und der Mißachtung in die sie geraten sind als vor der Katastrophe wie eine bestimmte Art ihrer Überlieferung, ihre 'Würdigung als Erbe' sie sehr oft darstellt. - Sie werden durch die Aufweisung des Sprungs in ihnen gettret. - Es gibt eine Überlieferung, die Katastrophe ist (GS V/1: 591).

El problema entonces se concentra en la ruptura de la tradición, que debe recomponerse desde una perspectiva de la discontinuidad. La exposición de lo humano en el marco de la desacralización histórica implica la caída en la mitificación encubierta:

Das urgeschichtliche Moment im Vergangenen wird - auch dies Folge und Bedingung der Technik zuglech - nicht mehr, wie einst - durch die Tradition der Kirche und Familie verdeckt. Der alte prähistorische Schauer umwittert schon die Umwelt unserer Eltern, weil wir durch Tradition nicht mehr an sie gebunden sind (GS V/1: 576). 
Benjamin analiza las consecuencias de esta determinación de la técnica que crea, mediante la descomposición de las formas antiguas, nuevas maneras perceptivas que convierten a su vez a lo antiguo en prehistórico. La historia comienza una y otra vez a escribirse de cero y el mito renace y se fortalece en la atmósfera secularizada de la Modernidad capitalista. De esta forma, la continuidad mítica de la tradición secularizada se presenta como linealidad temporal homogénea y logra encubrir las fisuras revolucionarias con el discurso del homenaje al pasado. Benjamin escribe en Das Passagen-Werk:

Die Würdigung oder Apologie ist bestrebt, die revolutionären Momente des Geschichtsverlaufes zu überdecken. Ihr liegt die Herstellung einer Kontnuität am Herzen. Sie legt nur auf diejenigen Elemente des Werkes wert, die schon in seine Nachwirkung eingegangen sind. Ihr entgehen die Stellen, an denen die Überlieferung abbricht und damit ihre Schroffen und Zacken, die dem einen Halt bieten, der über sie hinausgelangen will (GS V/1: 592).

Una continuidad de la discontinuidad es la fórmula de la dialéctica de la nueva tradición que Benjamin se plantea como alternativa a la falsificación historiográfica dominante. Pero las formas de lo nuevo se vuelven fantasmagoría en cuanto intentan una renovación sin un quiebre. Por ello, Benjamin concibe lo nuevo desde las formas de la tradición misma: su filosofía es una construcción política materialista desde una matriz de la tradición místico-religiosa, esta matriz aporta la transmisibilidad y comunicabilidad necesarias. ${ }^{22}$ Por tal motivo se propone el desprendimiento dialéctico entre sensación y tradición: "Bis ins letzte aus dem Bild der Geschichte 'Entwicklung' herauszutreiben und das Werden durch dialektische Zerreißung in Sensation und Tradition als eine Konstellation im Sein darzustellen, ist auch die Tendenz dieser Arbeit" (GS V/2: 1013s.). De allí que el estudio de la experiencia sea central e inseparable del análisis de la tradición para la redención de la imagen de la historia construida por la historiografía burguesa. La necesidad de separar tradición de sensación radica en el acto mismo de depurar lo ideológico del punto nodal en el que Benjamin se centra para fundar la posibilidad transformadora y construir una tradición alternativa: el sentir humano mismo.

\footnotetext{
${ }^{22}$ John MCCOLE ha desarrollado esta interpretación en profundidad en su estudio de 1993. Su explicación del concepto de tradición en Benjamin es clara al respecto: "Lo que él quería decir con 'tradición' era más la coherencia, comunicabilidad y por lo tanto la transmisibilidad de la experiencia que un canon particular de textos o valores" (1993: 2, la trad. es mía).
} 
En este marco, la experiencia como continuidad es la herramienta que pone en juego una alternativa a la tradición desde las estructuras mismas de la tradición. La Erfahrung benjaminiana debía responder en un plano subjetivo a la construcción de la imagen dialéctica en el plano del discurso objetivo del materialismo histórico. En las reflexiones sobre el concepto de la historia, se hace explícita la preocupación de Benjamin por deslindar a la política de la tradición (GS I/2: 698). Es en la persistencia en la representación de la historia de la tradición burguesa donde Benjamin encuentra las causas de la derrota de la política frente al fascismo. La discursividad lineal de la política llevó a los dirigentes a confiar en tres elementos de la tradición burguesa que terminarían por hacer fácil el ascenso del fascismo, estos son: la creencia en el progreso, la confianza en la base de masas y el servilismo al aparato institucional (GS I/2: 698). Los valores transmitidos por la tradición muestran aquí su carácter político y su capacidad de guiar la acción. La transmisión está dada entonces por medio de la narración del pasado; de allí que Benjamin proponga como forma de la tradición materialista la sustitución de la narración por la imagen. ${ }^{23} \mathrm{Y}$ aquí se hace evidente el interés en experimentos narrativos como los de Kafka, en cuyo caso la ruptura del contenido de la doctrina se da junto a una reconstrucción sobre fragmentos discontinuos de las estructuras narrativas de la tradición.

Que Benjamin se plantea el problema de la tradición como una tarea históricopolítica se percibe en los textos preparatorios para sus reflexiones sobre el concepto de historia. Allí escribe: “Aufgabe der Geschichte ist, der Tradition der Unterdrückten habhaft zu werden" (GS I/3: 1236), definiendo su historia como discontinuidad (íd.). ${ }^{24}$ Entra en juego entonces la dialéctica del detenimiento como shock de imágenes, se trata de comprender la historia desde una tradición crítica y por lo tanto política. En una nota aislada escrita hacia 1939 Benjamin define la historia de la siguiente manera: "Geschichte ist Chock zwischen Tradition und der politischen Organisation” (GS VI: 98). La noción de historia materialista aquí definida en términos de tradición y organización política implica la confrontación dialéctica de imágenes que producen un

\footnotetext{
${ }^{23}$ Como segundo aspecto de la doctrina elemental del materialismo histórico propone: "Geschichte zerfällt in Bilder, nicht in Geschichten" (GS V/1: 596).

${ }^{24}$ El texto sostiene: "Die Geschichte der Unterdrückten ist ein Diskontinuum" (GS I/3: 1236). Sin embargo, como ya se ha mencionado, para la visión del materialismo dialéctico, su tradición se encuentra regulada por la idea de continuidad, cf., V/1: 459s.
} 
shock. Se trata de la imagen dialéctica que Benjamin delinea en esa misma época. Según esta interpretación, la historia se halla así en una doble tensión dialéctica: entre los polos de la tradición y la organización política y los de la continuidad y la discontinuidad. La organización política burguesa se sostiene en una concepción de la historia como continuidad legitimada por la tradición. Mantiene así su fuerza en cuanto forma, pero la pone en shock mediante la introducción de la concepción discontinua del tiempo histórico. Es precisamente el olvido absoluto de la tradición del pasado de los oprimidos lo que constituyó para Benjamin la traición de la socialdemocracia a la organización política progresista que se proponía. Por tal motivo, sostiene Benjamin que la lectura del materialismo dialéctico se dirige a la recuperación de una tradición continua de los oprimidos. La tradición del proletariado no debe ser subordinada a las reivindicaciones utópicas futuras, sino elaborada en las reivindicaciones utópicas pasadas que la constituyen como tradición. BENJAMIN escribe:

Beim Proletariat entsprach dem Bewußtsein des neuen Einsatzes keine historische Korrespondenz. Es fand keine Erinnerung statt. [...] Es ist die Tradition der Unterdrückten, in der die Arbeiterklasse als die letzte geknechtete, als die rächende and als die befreiende Klasse auftritt. Von diesem [sic] Bewußtsein ist von der Sozialdemokratie von Anfang an preisgegeben worden. Sie spielte der Arbeiterschaft die Rolle der Erlöserin kommender Generation zu. Sie durchschnitt damit die Sehne ihrer Kraft (GS I/3: 1236s.).

La fuerza del pasado de la tradición no debe ser entonces subsumida en la linealidad progresiva de un futuro que constituya esta fuerza en un ideal vacío. La crítica de Benjamin a la socialdemocracia es aquí muy cercana a la de Sorel, a quien Benjamin había leído con interés. La "utopía" rechazada por el pensador francés era la ideología propia del parlamentarismo intelectualista que había traicionado los ideales radicales revolucionarios. ${ }^{25}$ Pero a diferencia de Sorel, quien también contrapone la imagen a la representación como camino alternativo a la traición socialdemócrata, Benjamin encuentra una respuesta válida en la construcción de una conciencia a través de la noción de experiencia. Lo vital, que en Sorel posee una centralidad determinante en la evaluación de la teoría política, en Benjamin se muestra mediado por elementos

\footnotetext{
${ }^{25}$ Para un análisis de las influencias de Sorel en Benjamin, cf. KAMBAS, 1992.
} 
marxistas incorporados a través de distintas lecturas que modifican su pensamiento a partir de mediados de los años veinte. ${ }^{26}$

La estructura de la tradición en tensión con la organización política implica una nueva concepción de la historia que no se inmovilice en la continuidad lineal de los hechos, ni se presente como ruptura discontinua arbitraria. El elemento contra el que Benjamin lucha, lo mítico, encuentra un lugar y un tiempo privilegiados en la tradición:

Was heißt das anderes als daß die Topographie der Aufriß dieses, wie jedes, mythischen Traditionsraums ist, ja der Schlüssel derselben werden kann, wie sie es dem Pausanias für Griechenland wurde, wie die Geschichte und Lage der pariser Passagen für dies Jahrhundert Unterwelt, in das Paris versank, es werden soll (GS V/1: 134).

El desafío del giro dialéctico, del giro político de la historiografía es encontrar la forma de una tradición de los oprimidos que no reproduzca la estructura mítica propia de la narración de la historia burguesa. Benjamin interpreta la narrativa de Kafka como una crisis de los contenidos doctrinarios de la tradición en el marco de las experiencias modernas y, como parte de estas experiencias, Kafka pone en juego una concepción de lo humano que Benjamin recuperará tardíamente desde la lectura de Gaston Bachelard.

\section{La humanidad kafkiana: entre el surrealismo y el expresionismo}

La importancia de Kafka en relación con las formulaciones políticas de los últimos años se evidencia también en las reflexiones en torno a la noción de humanidad. Así como Benjamin, en el contexto de análisis político del concepto de historia, piensa una definición de la imagen dialéctica fundada en la concepción de "humanidad redimida", 27 la lectura del narrador checo le aporta una visión instructiva para la crítica de dicho concepto. En efecto, en una fecha tardía de su biografía, entre los borradores y notas

\footnotetext{
${ }^{26}$ Las lecturas de Benjamin son, sin embargo, poco sistemáticas y fragmentarias. En este sentido, José SAZBÓN escribió que, a diferencia de "las empresas de reconstrucción del marxismo", como las de Lukács o Korsch, Benjamin "se limitó a interpolar la letra marxiana en el tejido conceptual de su propia teoría" (2002: 157). También BUCK-MoRss retomó la lectura benjaminiana de Marx y señaló que el exposé de 1935 de Das Passagen-Werk resultó "una contribución original a la teoría marxista" (2001: 144).

${ }^{27}$ En las anotaciones para el estudio del concepto de historia escribe: "Das dialektische Bild ist zu definieren als die unwillkürliche Erinnerung der erlösten Menschheit" (GS I/3: 1233).
} 
para una reelaboración del ensayo sobre Kafka, Benjamin apunta una clave para la comprensión de la humanidad kafkiana. Esta es quizás una de las últimas interpretaciones que hace Benjamin de Kafka. Sostiene allí que se debe tener en cuenta la comparación llevada a cabo por Gaston Bachelard en su Lautréamont de 1939 (GS II/3: 1264). Kafka aparece en este caso como contracara del poeta de los Cantos de Maldoror: lo que en éste es una "aceleración vital" y un frenesí y felicidad de la metamorfosis, en Kafka es una "pereza orgánica", una "catatonia progresiva" (BACHELARD 1985: 15ss.). Su metamorfosis es siempre una desgracia, un envilecimiento. BACHELARD escribe en los párrafos copiados por Benjamin:

A nuestro parecer, Kafka sufre un complejo de Lautréamont negativo, nocturno, negro. Y lo que tal vez prueba el interés de nuestras investigaciones sobre la velocidad poética y sobre la riqueza temporal es que la metamorfosis de Kafka aparece claramente como una disminución de la vida y de las acciones (ibíd.: 16).

Esta referencia al análisis de Bachelard es relevante por distintos motivos: por un lado, porque temporalmente indica que el interés en Kafka se extiende hasta el contexto último de producción de Benjamin; además señala una dirección interpretativa que pone en evidencia esa lectura de Kafka como particular intersección de surrealismo y expresionismo. ${ }^{28}$ Por último, aunque quizás como punto más importante, Kafka es recuperado en una lectura que pone énfasis en la animalidad kafkiana. Según esta interpretación, Kafka poetiza la animalidad humana, en él "el ser es captado así en su extrema miseria" (ibíd.: 18). La comparación con Lautréamont se dirige a subrayar ese empobrecimiento de las formas en el que "las ganas-de-vivir se agotan" (ibíd.: 20). Benjamin lo había leído como la poética de un fracasado en relación con su vínculo con la tradición, pero en esta última interpretación, recupera el descubrimiento de esa animalidad latente que constituye una "experiencia biológica profunda" en la que el psiquismo se coagula y la acción se lentifica (ibíd.: 17). Kafka pone en juego un aspecto de lo onírico que debe ser ganado como fuerza revolucionaria: "Kafka vive en un tiempo que muere" (ibíd.: 16), escribe Bachelard. Ese tiempo de lo biológico que

\footnotetext{
${ }^{28}$ En los apuntes a partir de septiembre de 1934, para la revisión de su ensayo sobre Kafka, BENJAMIN escribe: "Schematisch gesprochen stellt Kafkas Werk eines der sehr wenigen Verbindungsgleider zwischen Expressionismus und Surrealismus dar" (GS II/3: 1256). La confrontación con la lectura de Bachelard pone en evidencia también la peculiar intersección del pensamiento alemán con el francés, característica del trabajo interpretativo benjaminiano.
} 
muere, esa desaceleración de las funciones animales, debe ser analizado desde una perspectiva del presente; hay allí, en esa visión kafkiana de lo humano, una dimensión política que interesa a Benjamin.

La clave dialéctica de la tensión entre la mística y la política puede leerse entonces en este apunte escrito entre 1939 y 1940. Las transformaciones de lo biológico, que son, como sostiene Bachelard, uno de los polos del sueño, se presentan en la obra de Kafka como vida debilitada. ¿Será quizás esta una advertencia para Benjamin? ¿Será una advertencia que pone en evidencia el enfrentamiento de la vida con la muerte como fatalismo y que políticamente se traduce en ese peligro que en otro ensayo Benjamin llamó “melancolía de izquierda”? También allí, en la reseña de 1931 sobre Kästner, sostiene Benjamin que, bajo las condiciones actuales, lo bestial es en verdad la contracara de lo que se denomina "humanidad" (GS III: 283). Algunos años más tarde, en 1938, Benjamin le escribe a Scholem:

Das Kurze und Lange von der Sache ist, daß offenbar an nichts Geringeres als an die Kräfte dieser Tradition appelliert werden mußte, sollte ein Einzelner (der Franz Kafka hieß) mit der Wirklichkeit konfrontiert werden, die sich als die unsrige theoretisch z. B. in der modernen Physik, praktisch in der Kriegstechnik projiziert. Ich will sagen, daß diese Wirklichkeit für den Einzelnen kaum mehr erfahrbar, und daß Kafkas vielfach so heitere und von Engeln durchwirkte Welt das genaue Komplement seiner Epoche ist, die sich anschickt, die Bewohner dieses Planeten in erheblichen Massen abzuschaffen. Die Erfahrung, die der des Privatmanns Kafka entspricht, dürfte von großen Massen wohl erst gelegentlich dieser ihrer Abschaffung zu erwarten sein (BENJAMIN/SCHOLEM 1980: 271).

Con la interpretación que Benjamin recupera de Bachelard, se resignifica aquel contenido perdido de la narración correspondiente a la doctrina, que Benjamin tempranamente encontraba ya en Kafka. Lo corporal como función natural del hombre adquiere un sentido político al mostrarse como correlato del presente. Aparece por otra parte aquí la direccionalidad política de la interpretación que posee influencias de los intercambios con Brecht. $^{29}$

\footnotetext{
${ }^{29}$ Wizisla detalla los pormenores de las discusiones e intercambios de Benjamin y Brecht respecto a Kafka y señala acertadamente que, aunque Brecht criticó e incluso se molestó por algunos elementos del artículo de 1934, lo que éste se negaba a reconocer es que "el procedimiento de Benjamin no difería tanto del suyo: también trabajaba en la puesta al descubierto de las estructuras sociales sin el gesto radicalpragmático del poeta" (2007: 267s.). 
Comprender a Kafka como un Lautréamont negativo es entender su obra como un trabajo radiográfico de lo vital en el que lo que se percibe es una animalidad o una humanidad debilitada. Aquello que el surrealismo había sabido descubrir y que Benjamin reivindicaba en su ensayo de 1929, la fuerza de la embriaguez (Rausch) como capacidad transformadora, aparece en Kafka con un matiz oscuro, bajo, una metamorfosis en la que el cuerpo se expone como cuerpo disminuido y olvidado. El animal del hombre kafkiano se muestra a la sombra de una tradición que somete, pero su falta de vida y de acción actúa como revelación: ilumina el sentido de lo humano que Benjamin intenta resignificar en sus últimos años y que posee centralidad en su proyecto teórico político. ${ }^{30}$ En sus distorsiones, en su olvido, la humanidad en Kafka vive en un tiempo que muere y con ello su animalidad muestra la presencia y latencia de lo vital, en cuyas imágenes transitorias y nuevas la contingencia de la existencia también engendra imágenes revolucionarias.

\section{Referencias bibliográficas}

BACHElARD, Gaston. Lautréamont. México, Fondo de Cultura Económica, 1985.

BENJAMIN, Walter. Gesammelte Schriften (ed. R. Tiedemann y H. Schweppenhäuser), 7 tomos. Frankfurt a/M, Suhrkamp, 1972-1989. (= GS). / SCHOLEM, Gershom. Briefwechsel (ed. G. Scholem). Frankfurt a/M, Suhrkamp, 1980.

BuCK-Morss, Susan. Dialéctica de la mirada. Madrid, Visor, 2001.

HANSSEN, Beatrice. Walter Benjamin's Other History. Of Stones, Animals, Human Beings, and Angels. Berkeley y Los Angeles, University of Chicago Press, 2000.

KAMBAS, Chryssoula. "Walter Benjamin liest Georges Sorel: Réflexions sur la violence". In: Opitz, M./Wizisla, E. (eds.), "Aber ein Sturm weht vom Paradiese her”. Leipzig, Reclam 1992, 250-270.

LÖWY, Michael. Franz Kafka soñador insumiso. México, Taurus, 2007.

MCCOLE, John. Walter Benjamin and the Antinomies of Tradition. Ithaca-Londres, Cornell University Press, 1993.

MENNINGHAUS, Winfried. "Lo inexpresivo: las variaciones de la ausencia de imagen en Walter Benjamin". In: Massuh, Gabriela y Fehrmann, Silvia (eds.). Sobre Walter Benjamin. Vanguardias, historia, estética y literatura. Una visión latinoamericana. Buenos Aires, Alianza / Goethe-Institut Buenos Aires, 1993, 37-56.

SAZBón, José. "Historia y paradigmas en Marx y Benjamin". In: Historia y representación. Buenos Aires, Universidad Nacional de Quilmes, 2002, 56-178.

\footnotetext{
${ }^{30}$ Este interés en el concepto de lo humano se desarrolla también en su ensayo sobre Karl Kraus de 1931, en donde recupera las reflexiones del joven Marx (GS II/1: 334-367). 
Belforte, M. - Un Lautréamont Negativo

SCHOLEM, Gershom. Walter Benjamin. Historia de una amistad. Buenos Aires, Debolsillo, 2008.

WeIDNER, Daniel. "Das Überstürzen der Tradition. Das Problem der Lehre in den Debatten zwischen Benjamin und Scholem". In: Trajekte $\mathrm{N}^{\circ} 13$ (S. Weigel ed.), (septiembre 2006), 36-38.

WeIGEL, Sigrid. “Zu Franz Kafka”. In: LIDNER, Burkhardt (ed.), Benjamin Handbuch: LebenWerk-Wirkung. Stuttgart, Metzler, 2006, 543-556.

WizISLA, Erdmut. Benjamin y Brecht. Historia de una amistad. Buenos Aires, Paidós, 2007.

Recebido em 07/08/15

Aceito em 11/09/2015 